\title{
Reconhecimento das situações de emergência: avaliação pediátrica
}

\section{Systematic approach to the seriously ill or injured child: pediatric assessment}

Alessandra Kimie Matsuno

\begin{abstract}
RESUMO
Este texto apresenta uma revisão da avaliação pediátrica nas situações de emergência. A avaliação pediátrica sistemática permite o reconhecimento eficiente e rápido de sinais de insuficiência respiratória e/ou choque. O reconhecimento e o tratamento precoce dos pacientes nestas situações são fundamentais à prevenção da insuficiência cardiopulmonar e da parada cardíaca em crianças.
\end{abstract}

Palavras-chave: Emergências. Avaliação Pediátrica. Sinais Clínicos. Insuficiência Respiratória. Choque.

\section{Introdução}

A abordagem sistemática das crianças gravemente enfermas é a maneira mais rápida e eficiente de conduzir estes pacientes. Atualmente, esta abordagem é feita de forma padronizada em todos os programas de treinamento de suporte de vida. Em lactentes e crianças, a maioria das paradas cardíacas resulta de insuficiência respiratória e/ou choque. Por outro lado, o colapso súbito devido a arritmias ou outras causas cardíacas é menos comum. ${ }^{1}$ Quando a parada cardíaca ocorre, a evolução é ruim se comparada com a parada respiratória apenas, cuja sobrevida é em torno de $70 \%$, enquanto que em situações de parada cardíaca dentro do hospital a sobrevida é de aproximadamente $27 \%$, e fora do hospital, $5-12 \% .^{1}$ O objetivo da abordagem padronizada é permitir o reconhecimento das situações de emergência, principal- mente dos sinais de desconforto respiratório, insuficiência respiratória e choque, para poder intervir precocemente, impedindo que estas situações progridam para insuficiência cardiopulmonar e parada cardíaca. ${ }^{1,2,3}$

\section{Avaliação pediátrica}

O modelo "avaliar, categorizar, decidir e agir" é a abordagem sistemática escolhida para o reconhecimento e o tratamento das crianças gravemente enfermas ou vítimas de trauma. A avaliação inicial repetida permite que se determine o melhor tratamento ou intervenção em qualquer ponto cronológico. Com base na informação obtida na avaliação, é possível também categorizar as condições clínicas da criança por tipo e gravidade e decidir o tratamento mais adequado. Este processo de avaliar-classificar-decidir-agir é constante e repetitivo, devendo-se sempre reavaliar o paciente 
durante a ação e após cada procedimento. ${ }^{2}$ Por exemplo, após oferecer oxigênio, deve-se reavaliar se o paciente está respirando mais facilmente e se a cor e a condição mental estão melhorando. A avaliação pediátrica consiste em quatro partes: 1) Avaliação geral; 2) avaliação primária; 3) avaliação secundária; e 4) avaliação terciária.

\section{Avaliação geral}

Consiste em uma avaliação inicial visual e auditiva, realizada nos primeiros segundos de contato com o paciente. ${ }^{4}$ Deve-se avaliar simultaneamente a aparência, o trabalho respiratório e a circulação. Na aparência, avaliam-se o tônus muscular, a interação do paciente com o ambiente, a consolabilidade, o olhar e a fala ou o choro. Na avaliação do esforço respiratório, observa-se se há aumento do trabalho respiratório (batimento de asas do nariz, uso da musculatura acessória com retrações), diminuição ou ausência do trabalho respiratório (apneia, bradpneia), prestando-se atenção a sons anormais, como sibilos, gemidos e estridor audíveis sem o uso de estetoscópio. Na circulação, deve-se observar principalmente a coloração da pele (palidez, pele marmórea) e a presença de sangramentos. Com base nas informações da avaliação inicial, pode-se determinar se a condição do paciente indica ou não perigo de morte. ${ }^{5,6}$

\section{Avaliação primária}

Ao contrário da avaliação geral, que é visual e auditiva, a avaliação primária é prática e segue a seguinte abordagem: ${ }^{2}$
A) Abertura das vias aéreas
B) Breathing ou boa respiração
C) Circulação
D) Disfunção
E) Exposição

Durante cada passo da avaliação primária, deve-se procurar detectar qualquer anormalidade que indique perigo de morte. Se houver alguma, esta deve ser tratada antes de se concluir o resto da avaliação.

\section{A) Abertura das vias aéreas}

Pela avaliação da movimentação do tórax e do abdome, dos sons respiratórios e da movimentação do ar pelo nariz e pela boca, pode-se determinar se as vias aéreas estão livres, sustentáveis ou passíveis de manutenção com manobras simples, ou não sustentáveis, ou seja, que não podem ser mantidas sem inter- venções avançadas. As manobras simples de sustentação das vias aéreas incluem: ${ }^{1,2}$

- Posicionamento confortável e adequado da criança, visando melhorar a permeabilidade das vias aéreas.

- Uso de manobras para abrir as vias aéreas, como a inclinação da cabeça com elevação do queixo, quando não houver suspeita de lesão de coluna. Havendo suspeita de lesão de coluna, a manobra será a elevação da mandíbula, sem a extensão do pescoço; se esta manobra não for suficiente para abrir as vias aéreas, deve-se tentar a inclinação da cabeça com elevação do queixo, mesmo se houver lesão da coluna, já que a prioridade é a abertura das vias aéreas.

- Aspiração do nariz e da orofaringe.

- Realização de técnica de alívio de obstrução das vias aéreas por corpo estranho, em pacientes conscientes.

- Uso de cânula nasofaríngea ou orofaríngea.

As intervenções avançadas de suporte das vias aéreas são:

- Intubação traqueal.

- Uso de máscara laríngea.

- Uso de pressão positiva contínua de vias aéreas (CPAP).

- Remoção de corpo estranho por laringoscopia direta.

- Cricotireoidotomia.

\section{B) Breathing ou boa respiração}

Na avaliação da respiração, observam-se a frequência respiratória, o esforço respiratório, o volume corrente, os sons pulmonares e das vias aéreas, além da oximetria de pulso. ${ }^{2}$

\section{Frequência respiratória}

A Tabela 1 mostra a frequência respiratória normal de acordo com a idade. Frequência respiratória maior que 60 por minuto é considerada anormal em qualquer idade. ${ }^{1,2}$

A avaliação da frequência respiratória deve ser feita antes da manipulação da criança, pois a ansiedade e a agitação podem alterar a linha de base da frequência respiratória. Ressalta-se que quaisquer condições que aumentem a demanda metabólica, como dor e febre, podem aumentar a frequência respiratória. É preciso contar a frequência respiratória por pelo menos 30 segundos, pois durante o sono dos lacten- 


\section{Tabela 1}

Valores da frequência respiratória normal em incursões respiratórias por minuto (ipm) de acordo com a idade.

\begin{tabular}{lc}
\hline Idade & $\begin{array}{c}\text { Frequência } \\
\text { Respiratória (ipm) }\end{array}$ \\
\hline Recém-nascido & $30-60$ \\
Lactente (<1 ano) & $25-35$ \\
Crianças pequenas (1 -3 anos) & $20-30$ \\
Pré-escolares (4 - 5 anos) & $20-25$ \\
Escolares (6-10 anos) & $18-20$ \\
Adolescentes (>10 anos) & $12-16$ \\
\hline
\end{tabular}

tes, podem ocorrer pausas respiratórias de 10 a 15 segundos. Além disso, deve-se contar a frequência respiratória várias vezes, à medida que se avalia e reavalia o paciente; para isso, pode também ser usado um monitor cardiorrespiratório. ${ }^{2,7}$

A taquipneia acompanhada de esforço respiratório aumentado é, em geral, o primeiro sinal de alteração respiratória nos lactentes. A taquipneia sem esforço respiratório ou "taquipneia silenciosa" geralmente é resultado de condições não pulmonares ou da resposta fisiológica ao estresse, como febre alta, dor, acidose metabólica leve associada à desidratação ou sepse (sem pneumonia). ${ }^{8}$

A bradipneia é geralmente acompanhada de irregularidade da respiração e suas causas incluem fadiga, lesão do sistema nervoso central, hipotermia ou uso de medicações que deprimem a respiração. Em crianças gravemente doentes, constitui sinal clínico grave e perigoso, podendo sinalizar parada respiratória iminente. ${ }^{8}$

A apneia é a cessação do fluxo de ar inspirado por 20 segundos; se durar menos, mas for acompanhada de bradicardia, cianose ou palidez, também será considerada apneia. Dependendo da movimentação da musculatura inspiratória, pode ser dividida em três tipos:

- Apneia central: Ausência da atividade muscular inspiratória, ou seja, não há esforço nem tentativa de respiração. Geralmente, ocorre quando há anormalidade ou depressão do sistema nervoso central ou da medula espinhal.

- Apneia obstrutiva: Presença de atividade da musculatura inspiratória, mas sem fluxo de ar. A passagem do fluxo é bloqueada por obstrução de vias aéreas superiores, como nos lactentes com grande quantidade de secreção em vias aéreas.

- Apneia mista: Central e obstrutiva.

\section{Alterações do esforço respiratório}

- Batimento de asas do nariz: Alargamento das narinas em cada movimento inspiratório visando maximizar a entrada de fluxo de ar durante a respiração, comumente observado em lactentes e crianças pequenas. ${ }^{2,8}$

- Retrações torácicas: As retrações associadas a estridor ou roncos inspiratórios sugerem obstrução das vias aéreas superiores. As retrações acompanhadas de sibilos expiratórios sugerem obstrução acentuada de vias aéreas inferiores. As retrações acompanhadas de gemido expiratório ou de aumento do trabalho da respiração sugerem doença do tecido pulmonar (Tabela 2). ${ }^{2,9}$

\section{Tabela 2}

Tipo e características da retração torácica de acordo com o grau de dificuldade respiratória.

\begin{tabular}{lll}
\hline Grau de dificuldade respiratória & Tipo de retração torácica & Características da retração \\
\hline Leve a moderado & Subcostal & $\begin{array}{l}\text { Retração do abdome, imediatamente abaixo do } \\
\text { gradeado costal. } \\
\text { Retração do abdome, abaixo do esterno. }\end{array}$ \\
$\begin{array}{l}\text { Subesternal } \\
\text { Intercostal } \\
\text { tipos do grau leve a moderado) }\end{array}$ & Supraclavicular & Retração entre as costelas. \\
& Supraesternal & Retração do pescoço acima da clavícula. \\
& Esternal & Retração do tórax acima do esterno. \\
& & $\begin{array}{l}\text { Retração do esterno em direção à porção } \\
\text { anterior da coluna vertebral. }\end{array}$ \\
\hline
\end{tabular}


- Balanço da cabeça e respiração abdominal: São dois sinais clínicos de alerta, que indicam aumento do risco de deterioração do paciente. $\mathrm{O}$ balanço da cabeça ocorre quando o paciente usa os músculos do pescoço para ajudar na respiração. A criança eleva o queixo e estende o pescoço durante a inspiração, e durante a expiração, o queixo vai para frente. A respiração abdominal se caracteriza por retração do tórax enquanto o abdome se expande durante a inspiração, e na expiração ocorre o inverso, ou seja, o tórax se expande e o abdome se retrai. Este tipo de respiração é característico de lactentes e crianças com patologia neuromuscular, com ventilação ineficiente que pode evoluir rapidamente para fadiga. ${ }^{10}$

\section{Volume corrente}

O volume corrente normal é de 6 a $8 \mathrm{~mL} / \mathrm{kg}$ de peso. A avaliação clínica do volume corrente inclui a observação da expansibilidade torácica e a ausculta da movimentação distal do ar. A expansão torácica diminuída ou assimétrica pode ser causada por esforço respiratório inadequado, obstrução de vias aéreas, pneumotórax, hemotórax, derrame pleural, aspiração de corpo estranho e afecções do parênquima pulmonar. Quanto à ausculta da movimentação de ar, as áreas abaixo das axilas são as melhores para a avaliação da entrada de ar distal. Normalmente, os sons inspiratórios devem ser ouvidos distalmente como sons suaves e tranquilos que ocorrem simultaneamente com o esforço inspiratório, enquanto os sons expiratórios são geralmente curtos e discretos, ou mesmo ausentes. ${ }^{7}$

A ventilação minuto é o volume de ar que se movimenta para dentro e para fora dos pulmões a cada minuto (Equação 1). das vias aéreas superiores. Pode ser indicativo de obstrução crítica das vias aéreas que requer intervenção imediata. As causas de estridor são obstrução das vias aéreas por corpo estranho, infecção, anomalias congênitas das vias aéreas (laringomalácia), edema de vias aéreas superiores secundário a reações alérgicas ou trauma. ${ }^{9}$

- Gemido expiratório: Som curto e grave durante a expiração que ocorre à medida que a criança expira contra a glote parcialmente fechada. Constitui sinal de acometimento grave do tecido pulmonar, com colapso de vias aéreas de pequeno calibre e alvéolos, e reflete a tentativa da criança de aumentar a capacidade residual funcional pelo fechamento parcial da glote na expiração. As condições que podem causar este som incluem pneumonia, contusão pulmonar, edema pulmonar, síndrome do desconforto respiratório agudo e doença da membrana hialina. ${ }^{2,8}$

- Gargarejo: Som rude durante a inspiração e a expiração, resultante de obstrução das vias aéreas superiores por secreções, vômitos ou sangue. ${ }^{1,8}$

- Sibilo: Assobio agudo ouvido mais frequentemente durante a expiração, que indica obstrução das vias aéreas inferiores (intratorácicas). As causas mais comuns são asma e bronquiolite. $\mathrm{O}$ aparecimento de sibilos durante a inspiração sugere obstrução de vias aéreas superiores. ${ }^{1,7}$

- Estertores ou crepitações: Estalidos agudos ouvidos na inspiração, que podem ser úmidos ou secos. Os úmidos indicam acúmulo de fluido alveolar, como na pneumonia, e os estertores secos, descritos como o som produzido quando se esfregam fios de cabelo perto do ouvido, são mais comuns na atelectasia e nas doenças pulmonares intersticiais. ${ }^{2,7}$

Ventilação Minuto = Frequência respiratória x Volume corrente (Equação 1)

\section{Oximetria de pulso}

Constitui método não invasivo, que monitora a por-

Baseado nesta fórmula pode-se inferir que a hipoventilação, ou seja, um volume minuto baixo, pode ocorrer devido a frequência respiratória baixa ou volume corrente pequeno (observado no exame físico pela expansão torácica inadequada, respiração superficial, murmúrio vesicular diminuído ou alterado) ou frequência respiratória muito rápida, com volumes correntes muito pequenos. ${ }^{7}$

\section{Sons respiratórios e pulmonares anormais}

- Estridor: Som áspero, alto e de aparecimento mais comum durante a inspiração, que sinaliza obstrução centagem de hemoglobina saturada de oxigênio. Pode detectar hipoxemia em crianças, antes mesmo que ela se torne clinicamente aparente (com cianose e bradicardia). Ressalta-se que a oximetria deve ser interpretada levando-se em conta a frequência respiratória, o esforço respiratório e o nível de consciência do paciente, já que a criança pode estar com insuficiência respiratória, mas com saturação de $\mathrm{O}_{2}$ adequada. Considera-se oxigenação adequada quando a saturação de $\mathrm{O}_{2}$ é igual ou superior a $94 \%$ em ar ambiente. Quando estiver abaixo deste valor, deve-se oferecer oxigênio ao paciente. Caso a saturação persista abai- 
xo de $90 \%$, mesmo com oferta de $\mathrm{O}_{2}$ por meio de máscara não reinalante a $100 \%$, uma intervenção adicional deve ser feita. ${ }^{2}$

Outra situação que deve ser considerada cuidadosamente é a disparidade entre a frequência de pulso mostrada no oxímetro e aquela avaliada pela palpação e pela monitorização cardíaca. Caso isto ocorra ou a onda de pulso na oximetria esteja irregular ou ausente, deve-se verificar se há sinais de má perfusão da pele. Em casos de intoxicação por monóxido de carbono ou metahemoglobinemia, a oximetria de pulso não detectará a saturação de oxigênio de maneira precisa. No primeiro caso, ela detectará uma saturação falsamente elevada, pois o oxímetro de pulso reflete a saturação de $\mathrm{O}_{2}$ da hemoglobina normal, não a porcentagem de hemoglobina ligada ao monóxido de carbono. Em pacientes com metahemoglobinemia, se a porcentagem de metahemoglobina for superior a $5 \%$, a leitura permanecerá em $85 \% .{ }^{11}$

\section{C) Circulação}

A função cardiovascular deve ser avaliada pela temperatura e cor da pele, frequência e ritmo cardíaco, pressão arterial, pulsos, tempo de enchimento capilar e perfusão de órgãos-alvo.

\section{Temperatura e cor da pele}

A temperatura e a cor da pele devem ser semelhantes no tronco e nas extremidades. Quando há deterioração da perfusão cutânea, as mãos e os pés são geralmente os primeiros locais afetados, tornando-se frios, pálidos ou mosqueados; isto vai se estendendo para o tronco e depois para todo o corpo, conforme a gravidade do quadro. Recomenda-se estar atento à temperatura do ambiente, pois se estiver frio, pode haver vasoconstricção periférica, que também pode causar palidez e mosqueamento da pele. ${ }^{12}$

\section{Frequência cardíaca}

A Tabela 3 mostra a frequência cardíaca normal de acordo com a idade. ${ }^{2}$

A frequência cardíaca deve ser verificada pela avaliação do pulso e da ausculta e pela monitorização cardíaca. A taquicardia é uma resposta inespecífica e pode estar associada a várias condições de estresse, como febre, dor e ansiedade. A bradicardia pode ser uma condição normal em pacientes atletas, mas pode representar perigo iminente de parada cardíaca. Caso o paciente apresente bradicardia com sinais de má perfusão tecidual, deve-se iniciar intervenção com abordagem das vias aéreas e ventilação adequada. ${ }^{2}$

\section{Ritmo cardíaco}

Deve-se analisar e detectar padrões anormais de ritmo cardíaco pela monitorização cardíaca.

\section{Pressão arterial}

A hipotensão arterial é definida pelos limites de pressão arterial sistólica especificados na Tabela 4. É importante salientar que estes limites de pressão arterial se aproximam do percentil 5 da pressão arterial sistólica normal para a idade..$^{1,2}$

A medida correta da pressão arterial em crianças requer a utilização de esfigmomanômetro com manguito de tamanho apropriado. A parte interna de borracha, não a parte externa de tecido, deve cobrir pelo menos $2 / 3$ do comprimento do braço e envolver $80 \%$ a $100 \%$ de sua circunferência, com ou sem superposição. O uso de manguito muito pequeno resultará em valores falsamente elevados de pressão arterial.

\section{Tabela 3}

Valores de frequência cardíaca normal em batimentos por minuto (bpm) de acordo com a idade (média \pm 2 desvios-padrão).

\begin{tabular}{lc}
\hline Idade & $\begin{array}{c}\text { Frequência cardíaca (bpm) } \\
\text { (média } \pm 2 \text { desvios-padrão) }\end{array}$ \\
\hline Recém-nascido & $140 \pm 50$ \\
$1-6$ meses & $130 \pm 50$ \\
$6-12$ meses & $115 \pm 40$ \\
$1-2$ anos & $110 \pm 40$ \\
$2-6$ anos & $105 \pm 35$ \\
$6-10$ anos & $95 \pm 30$ \\
$>10$ anos & $85 \pm 30$ \\
\hline
\end{tabular}

\section{Tabela 4}

Definição de hipotensão arterial por idade e limites de pressão arterial sistólica (mm Hg).

\begin{tabular}{lc} 
Idade & $\begin{array}{c}\text { Pressão arterial } \\
\text { sistólica (mm Hg) }\end{array}$ \\
\hline Recém-nascidos a termo (0-28 dias) & $<60$ \\
Lactentes (1-12 meses) & $<70$ \\
Crianças 1-10 anos & $<70+(2$ x idade em anos $)$ \\
$>10$ anos & $<90$ \\
\hline
\end{tabular}




\section{Pulsos}

A palpação dos pulsos dá informações sobre a perfusão sistêmica. Devem-se avaliar os pulsos centrais (femoral, axilar e carotídeo) e periféricos (radial, pedioso e tibial posterior). O pulso carotídeo é tecnicamente mais difícil de palpar nas crianças abaixo de 1 ano, pois elas apresentam pescoços mais curtos e grossos. Quando ocorre diminuição do débito cardíaco, a perfusão sistêmica cai de maneira gradativa, iniciando-se com a redução dos pulsos periféricos até atingir os pulsos centrais; portanto, o enfraquecimento dos pulsos centrais é um sinal preocupante e pode indicar parada cardíaca iminente. Grande diferencial de pulso, com pulso periférico mais fraco que o central, que se mantém ainda forte, pode também ser sinal de vasoconstricção periférica, devendo-se verificar se a temperatura ambiente está fria.

A variação da amplitude de pulso de um batimento para outro pode ocorrer em crianças com arritmias; se esta variação ocorrer durante o ciclo respiratório (pulso paradoxal) pode ser um sinal de asma grave ou tamponamento cardíaco. A diminuição da amplitude de pulso no paciente intubado, concomitante à respiração com pressão positiva, pode sinalizar hipovolemia. $^{13}$

\section{Tempo de enchimento capilar}

Para a avaliação do tempo de enchimento capilar, eleva-se o membro superior do paciente levemente acima do nível do coração, e aplica-se uma pressão firme à falange distal do dedo indicador do paciente durante 5 segundos, contando-se o tempo até que a reperfusão do dedo seja completa. O tempo de enchimento capilar é considerado normal quando menor ou igual a 2 segundos. O prolongamento do tempo de enchimento capilar acima de 2 segundos é indicativo de má perfusão tecidual. As causas de aumento do tempo de enchimento capilar incluem desidratação, choque e hipotermia. Ressalta-se que a baixa temperatura do ambiente também pode prolongar o tempo de enchimento capilar. ${ }^{2,12}$

\section{Perfusão de órgãos-alvo}

\section{- Cérebro}

A perfusão cerebral é importante indicativo da circulação sistêmica. $\mathrm{O}$ exame neurológico inclui a avaliação do nível de consciência, do tônus muscular e dos reflexos pupilares. A perda da consciência, convulsões generalizadas, dilatação pupilar e perda do tônus muscular são sinais de hipóxia cerebral súbita e grave. Quando a hipóxia cerebral se desenvolve de maneira mais gradual, os sinais podem ser sutis e só percebidos quando se avalia o paciente repetidamente. Estes sinais incluem a alteração do nível de consciência, confusão mental, irritabilidade, letargia e agitação. Além da hipóxia, alguns medicamentos, condições metabólicas e o aumento da pressão intracraniana podem produzir sinais e sintomas neurológicos. ${ }^{1,2}$

\section{- Pele}

A cor da pele também pode refletir a perfusão periférica ou mesmo a função circulatória. A palidez, o mosqueamento e a cianose da pele podem indicar fornecimento insuficiente de oxigênio para os tecidos.

A palidez é o branqueamento da pele, cujas causas incluem: redução do fornecimento de sangue para a pele (frio, estresse, choque hipovolêmico), anemia ou redução da pigmentação da pele. A palidez é mais provável de ser clinicamente significativa quando associada à palidez da mucosa (lábios, língua, mucosa da boca ou mucosa ocular) e à palidez das extremidades (palmas das mãos e solas dos pés). Em crianças com pele mais escura ou espessa, a palidez é difícil de ser detectada.

O mosqueamento é a pele manchada com descoloração irregular ou em placas, com aspecto salpicado. Pode ocorrer em casos de hipoxemia, hipovolemia ou choque, em consequência de vasocontricção intensa, que ocasiona fornecimento irregular de sangue oxigenado, levando à cianose em algumas áreas. Pode também ser decorrente de variação na quantidade de melanina na pele.

A cianose é a coloração azulada da pele e das mucosas; pode ser periférica ou central. A cianose periférica afeta mãos e pés, e pode ser observada em situações de choque, insuficiência cardíaca congestiva, doença vascular periférica ou em condições que causam distensão venosa. A cianose central acomete as mucosas e a face e geralmente se associa a comprometimento cardiorrespiratório. Ressalta-se que a cianose só é evidente quando há aumento do conteúdo de desoxihemoglobina acima de $5 \mathrm{~g} / \mathrm{dL}$. Assim, em uma criança com hemoglobina de $16 \mathrm{~g} / \mathrm{dL}$ a cianose aparecerá quando houver saturação de oxigênio de $70 \%$, ou seja, $30 \%$ da hemoglobina ou 4,8 g/dL estão dessaturados. Por outro lado, se a concentração de hemoglobina for $8 \mathrm{~g} / \mathrm{dL}$, é necessária saturação de oxigênio arterial muito baixa (por volta de 40\%) para produzir cianose. Desta forma, a cianose pode estar presente com graus mais leves de hipoxemia na criança com policitemia, e pode não estar aparente, apesar 
de hipoxemia significativa, na criança anêmica. O desenvolvimento de cianose central geralmente indica necessidade de intervenção de emergência, como administração de oxigênio e suporte da ventilação. ${ }^{1,2,11}$

\section{- Perfusão renal}

O débito urinário adequado geralmente indica perfusão renal apropriada. A diurese é considerada normal quando acima de 0,5 a $1 \mathrm{~mL} / \mathrm{kg} / \mathrm{h}$ em recémnascidos e lactentes e acima de $12 \mathrm{~mL} / \mathrm{m}^{2} / \mathrm{h}$ ou 300 $\mathrm{mL} / \mathrm{m}^{2} /$ dia, em crianças mais velhas. Deve-se tomar cuidado na interpretação do débito urinário imediatamente após a colocação de sonda vesical, pois este representa a quantidade de urina armazenada anteriormente na bexiga e não o estado atual. ${ }^{1,2}$

\section{D) Disfunção}

Consiste na análise rápida dos componentes principais do sistema nervoso central: o córtex cerebral e o tronco encefálico. Esta avaliação deve ser feita ao final da avaliação primária e repetida durante a avaliação secundária, monitorando as alterações da condição neurológica da criança. Para a avaliação do nível de consciência, pode-se utilizar a escala de resposta pediátrica (AVDN) (Tabela 5$)^{2}$ ou a escala de coma de Glasgow (Tabela 6). ${ }^{14}$

O exame das pupilas é útil para avaliar a função do tronco encefálico. Deve-se avaliar o diâmetro pupilar (em mm), se há igualdade no tamanho das pupilas e se elas reagem à luz com constrição, verificando a magnitude e a rapidez desta resposta. $\mathrm{O}$ acrônimo

\section{Tabela 5}

Escala de Resposta Pediátrica (AVDN).

\begin{tabular}{|c|c|c|}
\hline $\mathrm{A}$ & Alerta & $\begin{array}{l}\text { A criança está acordada, ativa e responde adequadamente aos pais e aos estímulos externos. } \\
\text { Esta resposta adequada deve respeitar a idade e as condições prévias da criança. }\end{array}$ \\
\hline $\mathrm{V}$ & Voz & A criança responde somente quando os pais ou o examinador chamam seu nome ou falam alto. \\
\hline $\mathrm{D}$ & Dor & A criança só responde aos estímulos dolorosos, como aperto no leito ungueal. \\
\hline $\mathrm{N}$ & Não responsivo & A criança não responde a qualquer estímulo. \\
\hline
\end{tabular}

\section{Tabela 6}

Escala de Coma de Glasgow modificada para crianças.

\begin{tabular}{lc}
\hline ABERTURA OCULAR & ESCORE \\
\hline Espontânea & 4 \\
Ao comando verbal & 3 \\
À dor & 2 \\
Nenhuma & 1
\end{tabular}

MELHOR RESPOSTA VERBAL

\begin{tabular}{|c|c|c|}
\hline 0 - 23 meses & $2-5$ anos & $>5$ anos \\
\hline Sorri, balbucia & Palavras apropriadas & Orientado, conversa \\
\hline Choro apropriado & Palavras inapropriadas & Confuso \\
\hline Choro inapropriado & Choro, gritos & Palavras inapropriadas \\
\hline Gemidos & Gemidos & Sons incompreensíveis \\
\hline Nenhuma & Nenhuma & Nenhuma \\
\hline
\end{tabular}

MELHOR RESPOSTAMOTORA

$<1$ ano

$>1$ ano

Obedece ao comando

6

Localiza a dor

Localiza a dor

5

Flexão normal

Flexão normal

4

Flexão anormal

Flexão anormal

3

Extensão

Extensão

2

Nenhuma

Nenhuma

4

3

2

1

Legenda: A pontuação máxima para crianças abaixo de 1 ano é de 14, pois elas não são normalmente capazes de obedecer ao comando. 
PERRL (Pupilas de tamanho Equivalente, Redondas e Reativas à Luz) descreve as características pupilares normais. Se as pupilas não contraírem em resposta aos estímulos luminosos diretos, deve-se suspeitar de lesão no tronco. A diferença no tamanho das pupilas ou na resposta ao estímulo luminoso pode ocorrer devido a trauma ocular ou em condições que aumentam a pressão intracraniana. ${ }^{2}$

\section{E) Exposição}

É o componente final da avaliação primária e consiste em despir a criança para facilitar o exame físico dirigido. Caso se detecte hipotermia significativa, procede-se ao aquecimento do paciente. Durante a exposição, deve-se estar atento às evidências de trauma, como sangramentos e queimaduras ou marcas incomuns sugestivas de maus-tratos. Ao movimentar a criança com suspeita de lesão de coluna, devese tomar cuidado com a coluna cervical. ${ }^{1,2}$

As condições potencialmente fatais que podem ser detectadas na avaliação primária estão na Tabela 7.

\section{Avaliação secundária}

Consiste na realização de história e exame físico dirigidos. Recomenda-se o uso da regra mnemônica SAMPLE para identificar aspectos importantes da história da criança, conforme mostrado na Tabela 8. Depois da obtenção da história, realiza-se o exame físico mais detalhado. ${ }^{2}$

\section{Tabela 7}

Condições potencialmente fatais que podem ser detectadas na avaliação primária.
A. Abertura de vias aéreas
B. Boa Respiração
C. Circulação
D. Disfunções
E. Exposição

Obstrução total ou grave de vias aéreas.

Apneia, desconforto respiratório significativo, bradipneia.

Sem pulsos detectáveis, perfusão inadequada, hipotensão arterial, bradicardia.

Ausência de resposta, diminuição do nível de consciência.

Hipotermia significativa, sangramentos significativos, petéquias/ púrpuras sugestivas de choque séptico, distensão abdominal compatível com abdome agudo.

\section{Tabela 8}

Componentes da história dirigida.

\begin{tabular}{ll}
\hline Sinais e sintomas & Dificuldade para respirar \\
& Alteração do nível de consciência \\
& Agitação, ansiedade \\
& Febre \\
& Redução da ingestão por via oral \\
& Diarreia, vômitos \\
& Sangramentos \\
& Fadiga \\
& Tempo de evolução dos sintomas \\
& Medicações, alimentos, látex \\
Alergias & Uso de medicações \\
Medicações & Útima dose e horário das medicações \\
Passado médico & Condições de nascimento e antecedentes mórbidos \\
& Cirurgias anteriores \\
& Imunização \\
& Horário e natureza do último sólido ou líquido ingerido \\
Líquido e última refeição & Eventos que levaram à doença ou lesão atual \\
Eventos & Perigos no local \\
& Tratamento durante o intervalo desde o início da doença ou da lesão até o momento \\
& Tempo estimado de chegada \\
& \\
\hline
\end{tabular}




\section{Avaliação terciária}

Consiste nos exames auxiliares que visam identificar a presença e a gravidade das anormalidades respiratórias e circulatórias. O termo terciário não significa que esses exames serão colhidos em terceiro lugar; o momento de realizar os exames será ditado pela condição clínica do paciente. Por exemplo, a determinação rápida da glicemia pode ocorrer no início da avaliação. ${ }^{2}$

\section{Avaliação das anormalidades respiratórias}

\section{Exames complementares}

- Gasometria arterial: Capaz de detectar hipoxemia, hipercapnia e distúrbios do equilíbrio ácido-base. A gasometria do sangue arterial pode ser usada nas situações de emergência para confirmar a impressão clínica ou avaliar a resposta à terapia, mas ela não é necessária para identificar a insuficiência respiratória.

- Concentração de hemoglobina no sangue: Ajuda a determinar a adequação da capacidade de transporte de oxigênio, pois o oxigênio ligado à hemoglobina é o componente mais significativo do conteúdo total de oxigênio no sangue.

- Radiografia de tórax: Ajuda no diagnóstico de obstrução de vias aéreas, doença do tecido pulmonar, barotrauma e doenças pleurais, sendo útil também para verificar a posição do tubo traqueal.

- Taxa de pico de fluxo expiratório (peak flow): Taxa máxima de fluxo gerado durante uma expiração forçada. Na presença de obstrução de vias aéreas (p. ex., asma), os valores de peak flow são reduzidos, podendo-se usar medidas seriadas de peak flow comparativamente para avaliar a resposta à terapia. Este teste, entretanto, pode ser feito apenas naquelas crianças que estejam alertas e que consigam cooperar seguindo as instruções de fornecer um esforço expiratório máximo.

\section{Monitorização}

- Oximetria de pulso: Fornece estimativa não invasiva da saturação arterial de oxihemoglobina $\left(\mathrm{SaO}_{2}\right)$. Monitora a adequação da oxigenação do sangue e a resposta ao tratamento. Ressalta-se que a oximetria de pulso monitora somente a saturação de oxihemoglobina; ela não avalia o conteúdo de oxigênio do sangue, o fornecimento de oxigênio para os tecidos e a eficácia da ventilação (eliminação de $\mathrm{CO}_{2}$ ).

- Monitorização do $\mathrm{CO}_{2}$ expirado: Pode ser feita por métodos qualitativos e quantitativos. A avaliação qualitativa detecta somente a presença de $\mathrm{CO}_{2}$, sendo mais utilizada para confirmar a intubação traqueal (crianças acima de $2 \mathrm{~kg}$ ). A avaliação quantitativa é feita de maneira contínua pela capnografia, que serve para estimar o valor da $\mathrm{PaCO}_{2}$ em pacientes com débito cardíaco adequado e sem obstrução de vias aéreas inferiores. ${ }^{2}$

\section{Avaliação das anormalidades circulatórias}

\section{Exames complementares}

- Gasometria arterial: Os valores da gasometria não são confiáveis para indicar a gravidade da hipóxia tecidual, hipercapnia ou acidose, mas servem como medidas de seguimento para verificar se houve piora ou melhora da oxigenação tecidual.

- Saturação venosa central de oxigênio $\left(\mathrm{SvcO}_{2}\right)$ : Deve ser avaliada preferencialmente em sangue colhido da veia cava superior. Em condições normais, a saturação venosa central de oxigênio é em torno de $70 \%-75 \%$. Assumindo-se que a saturação arterial normal de oxigênio seja de $100 \%$, deve haver uma diferença entre a saturação arterial e venosa central de $\mathrm{O}_{2}$ (extração de $\mathrm{O}_{2}$ ) de $25 \%$ a $30 \%$. Se o fluxo sanguíneo para os tecidos for baixo, mais oxigênio será extraído pelas células e, portanto, a $\mathrm{SvcO}_{2}$ será baixa.

- Lactato arterial: Reflete o equilíbrio entre a produção e o metabolismo de lactato. Em pacientes gravemente doentes, o aumento das concentrações de lactato em sangue arterial pode estar relacionado com hipóxia tecidual e metabolismo anaeróbico. Constitui bom indicador de prognóstico e deve ser avaliado sequencialmente para verificar a resposta à terapêutica. Nem sempre o aumento das concentrações de lactato representa isquemia tecidual, mas pode estar associado a alterações metabólicas (p. ex., doenças mitocondriais e insuficiência hepática).

- Concentração de hemoglobina: Indica a capacidade de transporte de oxigênio pelo sangue.

- Radiografia de tórax: Útil para avaliar o tamanho do coração e a presença de edema pulmonar. A diminuição da área cardíaca sugere pré-carga reduzida, e o aumento da área cardíaca pode ocorrer em pacientes com insuficiência cardíaca e derrame pericárdico.

- Ecocardiografia: Avalia o tamanho das câmaras cardíacas, espessura da parede, contratilidade cardíaca, configuração e movimentação das valvas, 
espaço pericárdico, pressões ventriculares estimadas, posição do septo interventricular, anomalias congênitas.

\section{Monitorização}

- Monitorização invasiva da pressão arterial: Permite avaliação contínua da pressão sistólica e diastólica. O padrão das ondas arteriais pode fornecer informações sobre a resistência vascular sistêmica e comprometimento do débito cardíaco.
- Monitorização da pressão venosa central: Pode fornecer informações úteis para guiar a terapia com fluido e drogas vasoativas. Deve-se prestar atenção na tríade de pressão arterial baixa, pressão venosa central alta e taquicardia, que é compatível com contratilidade miocárdica inadequada, choque obstrutivo (causado por pneumotórax hipertensivo ou tamponamento cardíaco) ou obstrução do fluxo arterial pulmonar (hipertensão pulmonar grave ou embolia pulmonar). ${ }^{2}$

\begin{abstract}
This paper presents a review of the pediatric assessment in emergency situations. Systematic pediatric assessment is a quick and efficient way to recognize signs of respiratory failure and/or shock. Early recognition and treatment in a timely manner are essential to the prevention of cardiopulmonary insufficiency and cardiac arrest in children.
\end{abstract}

Keywords: Emergencies. Pediatric Assessment. Clinical Signs. Respiratory Failure. Shock.

\section{Referênclas Blbllográficas}

1. American Heart Association, PALS - Pediatric Advanced Life Support - Provider Manual. 2002.

2. American Heart Association, PALS - Pediatric Advanced Life Support - Provider Manual. 2006.

3. Schindler MB, Bohn D, Cox PN, McCrindle BW, Jarvis A, Edmonds J, et al. Outcome of out-of-hospital cardiac or respiratory arrest in children. N Engl J Med 1996; 335: 1473-9.

4. Dieckmann RA, Brownstein D, Gausche-Hill M. The pediatric assessment triangle: a novel approach for the rapid evaluation of children. Pediatr Emerg Care 2010; 26: 312-5.

5. Thompson M, Coad N, Harnden A, Mayon-White R, Perera R, Mant D. How well do vital signs identify children with serious infections in paediatric emergency care? Arch Dis Child 2009; 94: 888-93.

6. Ralston ME, Zaritsky AL. New opportunity to improve pediatric emergency preparedness: pediatric emergency assessment, recognition, and stabilization course. Pediatrics 2009; 123: 578-80.

7. Downes JJ, Fulgencio T, Raphaely RC. Acute respiratory failure in infants and children. Pediatr Clin North Am 1972; 19: 423-45.
8. Mellins RB, Chernick V, Doershuk CF, Downes JJ, Sinclair JC, Waring WW. Respiratory care in infants and children. Am Rev Respir Dis 1972; 105: 461-83.

9. Santamaria JP, Schafermeyer R. Stridor: a review. Pediatr Emerg Care 1992; 8: 229-34.

10. Singer JI, Losek JD. Grunting respirations: chest or abdominal pathology? Pediatr Emerg Care 1992; 8: 354-8.

11. Sinex JE. Pulse oximetry: principles and limitations. Am J Emerg Med 1999; 17: 59-67.

12. Gorelick MH, Shaw KN, Baker MD. Effect of ambient temperature on capillary refill in healthy children. Pediatrics 1993; 92: 699-702.

13. Sarti A, Savron F, Ronfani L, Pelizzo G, Barbi E. Comparison of three sites to check the pulse and count heart rate in hypotensive infants. Paediatr Anaesth 2006; 16: 394-8.

14. Holmes JF, Palchak MJ, MacFarlane T, Kuppermann N. Performance of the pediatric glasgow coma scale in children with blunt head trauma. Acad Emerg Med 2005; 12: 814-9. 